\title{
PERAN KELUARGA DALAM MENJAGA KESELAMATAN DAN KESEHATAN PASIEN DI INSTITUSI PELAYANAN KESEHATAN
}

\author{
Sri Lailan Nazmi Saragih \\ Email : lailansaragih9@gmail.com
}

\begin{abstract}
ABSTRAK
Pasien di rumah sakit merupakan individu yang sedang memiliki masalah kesehatan, sehingga dimungkinkan mengalami kesulitan memenuhi kebutuhan pribadi termasuk menjaga keselamatan senadiri, oleh sebab itu pasien membutuhkan dukungan dari keluarga dan tim kesehatan yang merawat. Keluarga merupakan unit paling dekat dengan pasien, dan merupakan perawat utama bagi pasien. Keluarga berperan dalam menentukan cara atau perawatan yang diperlukan pasien di rumah sakit. Keberhasilan perawat di rumah sakit akan sia-sia jika tidak diteruskan di rumah yang kemudian mengakibatkan pasien harus dirawat kembali (kambuh). Peran serta keluarga sejak awal perawatan di rumah sakit akan meningkatkan kemampuan keluarga merawat pasien di rumah sehingga memungkinkan pasien tidak kambuh atau dapat dicegah. Beberapa rumah sakit mengizinkan pasien untuk membawa alat komunikasi yang perlu digunakan. Hal ini juga terbukti dari hasil penelitian yang dilakukan di rumah sakit Amerika serikat bahwa dengan keterlibatan pasien maupun anggota keluarganya dalam merawat dan memberikan kesempatan kepada keluarga pasien untuk berkunjung ke rumah sakit lebih lama dapat menguragi resiko kecemasan yang berlebihan yang diderita oleh pasien.
\end{abstract}

Kata Kunci : Pasien, Keluarga, Keselamatan dan Kesehatan

\begin{abstract}
Patients in the hospital are individuals who have health problems, so it is possible to experience difficulties meeting personal needs including maintaining safety, therefore patients need support from their families and the caring health team. The family is the unit closest to the patient, and is the primary caregiver for the patient. Family plays a role in determining the method or treatment needed by patients in the hospital. The success of nurses in the hospital will be in vain if they are not continued at home which then results in the patient having to be treated again (relapse). The role of the family from the beginning of treatment in the hospital will increase the family's ability to care for patients at home so that it allows patients not to relapse or be prevented. Some hospitals allow patients to carry any communication tools they need to use. This is also evident from the results of research conducted in hospitals in the United States that with the involvement of patients and their family members in caring for and giving the patient's family the opportunity to visit the hospital for longer, it can reduce the risk of excessive anxiety suffered by patients.
\end{abstract}

Key Words : Patient, Family, safety and health 


\section{LATAR BELAKANG}

Asma bronkial merupakan penyakit kronik yang sering dijumpai pada anak maupun dewasa di negara berkembang maupun negara maju. Prevalensinya meningkat sejak dua dekade terakhir. Laporan dari Global Initiatif for Asthma (GINA) tahun 2012 perkiraan jumlah penderita asma didunia adalah 300 juta orang, dengan jumlah kematian yang terus meningkat hingga 180.000 orang per tahun. Prevalensi total asma bronkial di dunia diperkirakan 7,2\%, Indonesia sebesar $3,32 \%$ dan Provinsi Lampung 1,45\%. Data primer diperoleh melalui anamnesis, pemeriksaan fisik dan kunjungan ke rumah. Pasien mengeluh sesak saat membantu suami membersihkan kandang ayam dibelakang rumah. Sesak bersifat terus-menerus dan semakin memberat. Sesak sudah pernah dirasakan sebelumnya. Pasien tidak pernah membersihkan kandang ayam sebelumya. Data sekunder didapat dari rekam medis pasien. Faktor pencetus seperti stres, debu, kotoran hewan dapat mempengaruhi eksaserbasi asma dengan ditambah faktor psikososial dan faktor perilaku terhadap kesehatan serta pemanfaatan fasilitas kesehatan. Pelayanan dokter keluarga dalam terapi farmakologis maupun nonfarmakologis mampu menyelesaikan masalah kesehatan dan meningkatkan kualitas hidup pasien.

Data World Health Organization (WHO) juga menunjukkan data yang serupa bahwa prevalensi asma terus meningkat dalam 30 tahun terakhir terutama di negara maju. Hampir separuh dari seluruh pasien asma pernah dirawat di rumah sakit dan melakukan kunjungan ke bagian gawat darurat setiap tahunnya. Pengelolaan penyakit asma meliputi terapi nonfarmakologis dan farmakologis. Terapi nonfarmakologis dengan menghindari faktor pencetus, menjaga kebersihan lingkungan dan rutin kontrol ke dokter. Sedangkan terapi farmakologis dengan obat pelega maupun pengontrol saluran nafas ada yang disemprot dan diminum. Dijelaskan kepada pasien dan keluarga pasien bahwa terapi nonfarmakologis lebih penting dan bermakna daripada terapi farmakologis. Pasien diberitahu masih perlu memperbaiki pola hidupnya dan sering kontrol asma ke Puskesmas sebulan sekali serta meminum obat dan kurangi aktivitas fisik serta selalu sedia obat semprot pelega dirumah.

Peran keluarga merupakan suatu proses hubungan antara anggota keluarga dengan adanya hubungan timbal balik, umpan balik dan keterlibatan emosional. Peran keluarga dapat memberikan kekuatan satu sama lain dan kemampuan anggota keluarga menciptakan suasana saling memiliki, untuk memenuhi kebutuhan pada perkembangan keluarga, ini merupakan strategi preventif yang paling baik, untuk meningkatkan dukungan sosial keluarga yang adekuat dalam membantu anggota keluarga yang mengalami masalah dalam kesehatan dan membutuhkan perhatian. Keluarga yang baik akan berpengaruh positif, dan keluarga yang kurang baik akan berpengaruh negatif, misalnya keluarga yang melakukan perannya pada penderita penyakit maka akan muncul rasa lebih percaya diri (Efendi, 2009). Sesuai dengan fungsi pemeliharaan kesehatan keluarga mempunyai peran dan tugas di bidang kesehatan yang perlu dipahami dan dilakukan, mengenal masalah 
kesehatan merupakan kebutuhan keluarga yang tidak boleh diabaikan karena tanpa kesehatan segala sesuatu tidak berarti, hal sekecil apapun keluarga perlu mengenal perubahan yang dialami pada keluarga agar tidak sakit atau mengalami kekambuhan (Suprajitno, 2006). Faktor pemicu asma antara lain debu, polusi rokok yang ada di lingkungan sehari-hari, dan asma merupakan penyakit kronis, sehingga pasien membutuhkan pengobatan yang perlu dilakukan secara teratur untuk mencegah kekambuhan (Ikawati, 2006). Kekambuhan merupakan peristiwa timbulnya kembali gejala-gejala yang sebelumnya sudah diperoleh kemajuan atau sembuh (Yosep, 2006). Asma merupakan ganguan kronik pada paruparu yang ditandai dengan sesak nafas. Penderita asma memiliki saluran nafas yang sangat sensitif, Saluran nafas bereaksi dengan cara menyempit atau mengerut jika teriritasi sehinga menyulitkan keluar masuknya udara.

\section{METODE PENELITIAN}

Pengkajian ini menggunakan metode kualitatif yang dilakukan dengan cara mengumpulkan sebanyak-banyaknya data untuk dianalisis, yaitu dengan menggunakan literature view yang berkenaan dengan judul pembahasan yaitu mengenai Peran Keluarga dalam Menjaga Keselamatan dan Kesehatan pasien Asma Bronkhial di ruang rawat. Adapun Literature View yang digunakan adalah Buku Teks, Buku Referensi, Jurnal Elektronik, Reasearch, dan hasil skripsi. Dengan kata kunci Peran, Kualitas Pelayanan, dan Keperawatan. Dan Literature View yang digunakan dalam metode ini adalah sebanyak 11 Literature View yang diterbitkan 8 tahun terakhir.
Berdasarkan beberapa literature view, selain perawat dan dokter, anggota keluarga juga sangat berperan penting dalam kesembuhan pasien asma. Kehadiran keluarga sangat berpengaruh besar dalam perawatan pasien asma. Keluarga memiliki peran penting saat hadirnya penderita asma bronkial di keluarga mereka. Selain biaya perawatan yang cukup mahal, penderita juga membutuhkan perhatian yang lebih dari anggota keluarga . Dan pengobatan penyakit ini juga membutuhkan waktu sedikit lama. Penderita Asma Bronkial tidak dapat bernafas normal, sehingga membutuhkan seorang caregiver, yaitu seorang yang secara umum bias merawat dan mendukung penderita dalam masa pengobatan. Dalam hal ini, caregiver yang paling dekat adalah keluarga, karena keluarga merupakan perawat utama bagi penderita.

Selain berperan penting dalam merawat pasien, keluarga juga harus mengetahui masalah yang dihadapi pasien sehingga pasien terkena penyakit ini. Keluarga harus mengetahui pemahaman pasien terkait penyakit yang dideritanya, keluarga juga harus bias memberikan informasi yang benar terkait dengan informasi yang diminta oleh pasien, dan tetap memotivasi pasien untuk melakukan ibadah meski sedang dalam keadaan sakit. 


\section{PEMBAHASAN}

\section{Peran keluarga secara aktif dalam menjaga keselamatan pasien di pelayanan kesehatan}

1. Memberikan informasi yang benar, jelas, lengkap dan jujur

2. Mengetahui dan melaksanakan kewajiban serta tanggung jawab pasien maupun keluarga

3. Mengajukan pertanyaan-pertanyaan untuk hal yang tidak dimengerti

4. Memahami dan menerima konsekuensi pelayanan

5. Mematuhi dan menghormati peraturan rumah sakit

6. Memperlihatkan sikap menghormati dan tenggang rasa dalam proses bersama tim kesehatan mengelola pasien

7. Memenuhi kewajiban finansial yang disepakati

\section{Penerapan 6 Sasaran Keselamatan Pasien dan Peran Keluarga dalam Menjaga Keselamatan Pasien di pelayanan kesehatan}

1. Ketepatan identifikasi pasien

Pasien dalam keadaan tidak sadar, gelisah, mengalami gangguan penglihatan, gangguan pendengaran, gangguan proses pikir, mendapat obat bius, atau gangguan lain tidak mampu melakukan identifikasi diri dengan benar selain itu pasien yang pindah ruang tidak mampu bertukar tempat tidur saat perawatan di rumah sakit berisik mengalami ketidaktepatan identifikasi, maka rumah sakit menyusun sistem untuk memastikan identifikasi pasien sebagai individu yang akan menerima pelayanan adalah tepat dan jenis pelayanan atau pengobatan terhadap individu tersebut adalah sesuai.

Peran pasien dan keluarga untuk memastikan ketepatan identifikasi pasien adalah

a. Memberikan data diri yang tepat pada pada saat mendaftar sesuai dokumen data diri yang dimiliki . Data utama yang diperlukan adalah nama dan tanggal lahir

b. Selama rawat inap pasien dipakaikan gelang. pasien dan keluarga harus memahami fungsi gelang dan patuh menggunakan gelang tersebut selama rawat inap karena gelang tersebut dipakai oleh tim kesehatan guna memastikan kebenaran identitas dan faktor risiko pasien saat memberikan pelayanan

\section{Komunikasi efektif}

Pasien yang menjalani rawat inap dikelola oleh dokter dan berbagai profesi lain sebagai tim dengan menerapkan sistem komunikasi yang efektif untuk memberikan pelayanan

Peran Keluarga mewujudkan komunikasi efektif adalah:

a. Menunjuk atau menetapkan anggota keluarga yang diberi kewenangan 
untuk berkomunikasi dengan tim kesehatan. Penunjukkan ini diperlukan untuk memastikan komunikasi berlangsung efektif dan berkesinambungan, tidak mengalami rantai komunikasi yang panjang dan kompleks yang berisiko menyebabkan perubahan makna isi informasi.

b. Memberikan informasi dan data terkait kondisi pasien kepada tim kesehatan dengan benar dan jelas.

c. Memberikan informasi pada petugas bila ada kejadian tidak diharapkan.

d. Meminta informasi yang diperlukan kepada tim kesehatan

\section{Pemberian obat secara aman}

Pemberian obat merupakan bagian yang mengambil porsi dominan dalam tata kelola pasien rawat inap..

a. Memberikan informasi yang lengkap tentang riwayat obat yang pernah dipergunakan sebelum masuk rumah sakit

b. Memberikan informasi tentang riwayat alergi atau reaksi yang dialami saat menggunakan obat tertentu

c. Mendukung pengawasan pemberian obat selama rawat inap dengan cara memastikan identitas pasien benar, menanyakan jenis obat yang diberikan, tujuan pemberian, dosis dan waktu pemberian obat

4. Kepastian Tepat-Lokasi, Tepat-Prosedur, Tepat-Pasien Operasi

Tindakan operasi merupakan salah satu prosedur yang mungkin dilakukan pada pasien untuk mengatasi masalah kesehatannya. Bagian tubuh yang akan dioperasi bisa meliputi bagian yang bersisi (misalnya tangan atau kaki kanan dan kiri, mata kanan dan kiri) atau bagian yang multipel level (misalnya tulang belakang) atau bagian yang multipel struktur (misalnya jari tangan) dengan demikian diterapkan sistem untuk memastikan tindakan tepatlokasi, tepat-prosedur, tepat-pasien. Salah satu prosedur yang dilakukan sebelum tindakan operasi adalah proses verifikasi. Peran pasien dan keluarga dalam proses verifikasi praoperasi adalah memberikan informasi yang benar dan bekerja sama secara kooperatif Proses yang dilakukan meliputi Verifikasi lokasi, prosedur, dan pasien yang benar.

Proses ini dilakukan dengan membuat tanda pada lokasi yang dioperasi. Penandaan lokasi operasi ini melibatkan pasien, dibuat oleh dokter yang akan melakukan tindakan dan dilaksanakan saat pasien dalam keadaan sadar .Tanda ini tidak boleh dihapus dan harus terlihat sampai saat akan disayat.

Memastikan bahwa semua dokumen, foto (imaging), hasil pemeriksaan yang relevan tersedia, diberi label dengan baik

Melakukan verifikasi ketersediaan peralatan khusus yang dibutuhkan.

5. Pengurangan risiko infeksi terkait pelayanan kesehatan

Rumah sakit merupakan tempat yang memungkinkan berkumpulnya berbagai jenis kuman sedangkan pasien yang sedang dirawat memiliki daya tahan tubuh relatif rendah dengan demikian diperlukan suatu proses bersama untuk mencegah timbulnya infeksi lain yang tidak berhubungan dengan penyakit utama pasien

Peran pasien dan keluarga dalam pengurangan risiko terkait pelayanan kesehatan adalah

a. Menerapkan prosedur cuci tangan yang benar 
Keluarga memiliki kemungkinan sering kontak dengan pasien, maka untuk melindungi diri sendiri dan melindungi pasien dari perpindahan kuman disarankan keluarga menerapkan prosedur cuci tangan yang benar pada 5 (lima) momen yaitu saat sebelum kontak dengan pasien, sesudah kontak pasien, sesudah ke toilet, sebelum dan sesudah makan. Perlu diperhatikan juga bahwa lingkungan sekitar pasien berisiko terpapar kuman maka disarankan mencuci tangan sesudah kontak dengan lingkungan pasien (meja, alat tenun, tempat tidur dsb),

b. Menerapkan etika batuk yang benar Keluarga dan pengunjung yang batuk berisiko menyebarkan kuman melalui partikel halus di udara dengan demikian bila sedang mengalami batuk keluarga perlu menggunakan masker atau menerapkan tehnik perlindungan yang benar saat batuk yaitu menutup mulut dan hidung menggunakan lengan.

\section{Pengurangan Risiko Pasien Jatuh}

Individu yang sedang sakit memiliki keterbatasan dalam pengamanan diri termasuk menghindari jatuh. Rumah sakit mengambil tindakan untuk mengurangi risiko dengan melakukan pengkajian faktorfaktor yang dapat menyebabkan jatuh seperti, penggunaan obat, gaya jalan dan keseimbangan, alat bantu berjalan yang digunakan oleh pasien, riwayat jatuh saat berjalan atau saat istirahat baring di tempat tidur.

Peran pasien dan keluarga dalam mencegah jatuh saat dirawat di rumah sakit adalah a. Pastikan penanda pasien beresiko jatuh berupa gelang kuning dipakai pasien

b. Jangan melepas atau memindah kartu kuning yang dipasang petugas dekat tempat tidur pasien atau di depan kamar pasien karena kartu tersebut merupakan penanda untuk mewaspadai pasien yang beresiko jatuh

c. Keluarga atau pasien perlu memastikan diri untuk memahami informasi yang diberikan oleh petugas agar dapat mendukung tindakan pencegahan jatuh.

d. Informasi yang perlu diketahui adalah:

$\checkmark$ faktor resiko jatuh yang teridentifikasi seperti obat yang dipergunakan, kesadaran pasien, keseimbangan saat berjalan,dll

$\checkmark$ tindakan pencegahan jatuh yang perlu dilakukan

$\checkmark$ cara untuk minta bantuan

$\checkmark$ cara menggunakan bel atau sarana komunikasi di ruangan

$\checkmark$ cara mengatur pengamanan tempat tidur

$\checkmark$ pengggunaan tali pengaman, dll

\section{KESIMPULAN}

Dari Uraian diatas, dapat disimpulkan bahwa Keluarga sangat berepran penting dalam perawatan pasien Asma Bronkhial. Karena pasien yang sedang sakit memiliki keterbatasan dalam melakukan aktivitas. Asma adalah suatu keadaan dimana saluran nafas mengalami penyempitan karena hiperaktivitas terhadap rangsangan tertentu, yang menyebabkan peradangan. Oleh karena itu, keluarga pasien harus tetap berada disamping pasien, mendukung pasien dalam menjalani perawatan. Dalam hal nya, disini keluarga berperan sebagai cargiver yang sangat dubutuhkan oleh pasien. 


\section{SARAN}

1. Bagi Profesi Perawat

Untuk Perawat, agar bias memberikan pendidikan kepada keluarga pasien. Hal ini berguna bagi keluarga pasien sebagai pendamping atau perawat dari pihak keluarga. Selain itu, agar keluarga pasien mengerti bagaimana cara merawat pasien asma Bronkhial.

2. Bagi Pihak Keluarga

Keluarga sebagaui caregiver agar dapat terus melatih dan merawat pasien secara produktif guna mempercepat proses penyembuhan pasien. Selain itu, keluarga harus tau tanda dan gejala saat penyakit pasien kambuh dan dapat memenuhi kebutuhan aktivitas seharihari pasien.

\section{DAFTAR PUSTAKA}

Bakar, N. A., \& Sari, N. N. (2017). Pengetahuan dan Sikap Keluarga Pasien Rawat Inap Rumah sakit Haji Surabaya. Jurnal Manajemen Kesehatan Universitas Airlangga, 3(1), 49-54.

Fitriana, Y., \& Pratiwi, K. S. (2018). Pelaksanaan Patient Safety di Rumah Sakit Umum Daerah dan di Rumah Sakit Umum Swasta Bantul Berdasarkan Ketentuan UndangUndang Nomor 44 tahun 2009 Tentang Rumah Sakit. Jurnal Kebidanan, 7(1).

Herawati, Y. T. (2015). Budaya Keselamatan Pasien di Ruang Rawat Inap Rumah Sakit X Kabupaten Jember. Jurnal IKESMA, 11.
Ismainar, H. (2019). Keselamatan Pasien di Rumah Sakit. Yogyakarta: Deepublish.

Juniarti, N. H., \& Mudayana, A. A. (2018). Penerapan Standar Keselamatan Pasien di Rumah Sakit Umum Daerah Provinsi Nusa Tenggara Barat. Jurnal Kesehatan Poltekkes Tarnate, 11(2).

Lambogia, A., Rottie, J., \& Karundeng, M. (2016). Hubungan Perilaku dengan Kemampuan Perawat dalam Melaksanakan Keselamatan Pasien (Patient Safety) di Ruang Akut Instlasi Gawat Darurat. e-Journal Keperawatan, 4(2).

Manurung, N. (2019). Hubungan Keluarga Bidang Kesehatan Terhadap Relaps Penderita Asma Bronkhiale di Pantai Labu Deli Serdang (Vol. 5).

Pae, K. (n.d.). Studi Fenomelogi : Pengalaman Keluarga dalam Mendampingi Pasien saat Proses Resusitasi di Instlasi Gawat darurat RSUD DR. Saiful anwar Malang. JUrnal Kesehatan Wiraraja Medika, 91-93.

Silfa, A. B., Hardisman, \& Pabuti, A. (2018). Analisis Hubungan Pengetahuan dan Persepsi Pasien dengan Partisipasi Pasien di Instlasi Paviliun Ambun Pagi RSUP DR. M. DJamil Padang. Jurnal Kesehatan Andalas, 7(2).

Simamora, R. (2019). Buku Ajar pelaksanaan Identifikasi Pasien. Uwais Inspirasi Indonesia. 
Tutiani, L., \& Krisanti, P. (2017). Menejemen Keselamatan Pasien. Jakarta: Kementrian Kesehatan Republik Indonesia.

Utami, N. M. (2013). Hubungan Antara Dukungan Sosial Keluarga dengan Penerimaan Dini Individu yang Mengalami Stress. Jurnal Psikologi Udayana, 1(1). 